\title{
Application of a Non-Mixture Cure Rate Model for Analyzing Survival of Patients with Breast Cancer
}

\author{
Ahmad Reza Baghestani' ${ }^{1}$, Sahar Saeedi Moghaddam ${ }^{2,1 *}$, Hamid Alavi Majd ${ }^{1}$, \\ Mohammad Esmaeil Akbari², Nahid Nafissi ${ }^{2}$, Kimiya Gohari ${ }^{1}$
}

\begin{abstract}
Background: As a result of significant progress made in treatment of many types of cancers during the last few decades, there have been an increased number of patients who do not experience mortality. We refer to these observations as cure or immune and models for survival data which include cure fraction are known as cure rate models or long-term survival models. Materials and Methods: In this study we used the data collected from 438 female patients with breast cancer registered in the Cancer Research Center in Shahid Beheshti University of Medical Sciences, Tehran, Iran. The patients had been diagnosed from 1992 to 2012 and were followed up until October 2014. We had to exclude some because of incomplete information. Phone calls were made to confirm whether the patients were still alive or not. Deaths due to breast cancer were regarded as failure. To identify clinical, pathological, and biological characteristics of patients that might have had an effect on survival of the patients we used a non-mixture cure rate model; in addition, a Weibull distribution was proposed for the survival time. Analyses were performed using STATA version 14. The significance level was set at $P \leq 0.05$. Results: A total of 75 patients $(\mathbf{1 7 . 1 \%})$ died due to breast cancer during the study, up to the last follow-up. Numbers of metastatic lymph nodes and histologic grade were significant factors. The cure fraction was estimated to be $58 \%$. Conclusions: When a cure fraction is not available, the analysis will be changed to standard approaches of survival analysis; however when the data indicate that the cure fraction is available, we suggest analysis of survival data via cure models.
\end{abstract}

Keywords: Breast cancer - long-term survival analysis - non-mixture cure rate model

Asian Pac J Cancer Prev, 16 (16), 7359-7363

\section{Introduction}

Medical researchers are largely interested in studying the effect of multi-explanatory variables on the time to occurrence of a specific event; the event can be death, relapse of a specific event, divorce, recurrence of a disease, and so forth. When the analysis of survival data is mainly aimed to estimate the effect of a covariate, the Cox's proportional hazard model as a semi-parametric approach is the most frequently-used method (Yu, 2008). Typically when using models for survival data, if the period of follow-up is sufficiently long, all patients will be eventually susceptible to experience the event under the study (Cox, 1972). One of the most important characteristics of survival data is the presence of censored observation, that are actually either lost during the followup or are the cases who do not experience the event under the study during the period of study. Also, for some outcomes, there may be some cases who never face the event of interest (Lambert, 2007).

As a result of significant progresses made in treatment of many types of cancers during the last few decades, there have been an increased number of patients who do not experience the event under study (Lambert et al., 2007; Rondeau et al., 2013). The cases that never experience the event of interest are referred to as cured, immune, or nonsusceptible. For example, researchers may be interested in analyzing the rejection of an organ transplanted. Many cases may never reject transplanted organ; therefore, a cured fraction of the population exists. With present of cure fraction in data, standard survival analysis methods such as Cox's proportional hazard model or log-rank test may not be appropriate because they do not account for the possibility of cure (Arano et al., 2010). Cure rate models (also known as long-term survival models) which are a special type of survival analysis models were developed to be used in such a situation.

Cure fraction can be of importance for patients, clinicians, and policy makers, and it may give more valuable insights into time trends in survival analysis of cancer patients (Andersson et al., 2011). Due to significant progress in therapies in recent years, there has been an increased focus on analyzing survival data via these type of models in all fields (Corbière and Joly, 2007; Ortega 
Ahmad Reza Baghestani et al

et al., 2014). Moreover, these survival models are known as split population models in the field of economists and other social scientists (Schmidt and Witte, 1989). Cure rate models are applicable for various types of cancers such as prostate, breast, melanoma, non-Hodgkin's lymphoma, leukemia, and head and neck cancer, in which a significant proportion of cases are immune of the event under study (Chen et al., 1999; Ortega et al., 2008). When the survival curve has a stable plateau at the end of the study it is recommended to use cure rate models for analyzing the survival data (Kim et al., 2013). Further, in the absence of cure fraction, cure rate models will be changed to standard survival analysis models (Yu, 2008).

The aim of the current study was to investigate the effects of clinical, pathological, and biological characteristics of patients on survival of patients with breast cancer using non-mixture cure rate model.

\section{Materials and Methods}

We studied 438 female patients with breast cancer who were visited and treated at Cancer Research Center in Shahid Beheshti University of Medical Sciences, Tehran, Iran. These patients were diagnosed from 1992 to 2012 and followed up until October 2014. We had to exclude some patients because of their incomplete information. The patients or patients' family members were contacted via phone calls to confirm whether the patients are still alive or not. Deaths due to breast cancer were regarded as failure and survival time was calculated as the time interval between date of cancer diagnosis and date of death due to breast cancer (for those who died) and date of the last follow-up (for those who were alive).

There are two major approaches in cure rate models. The oldest one which was introduced by Boag in 1949 is the mixture cure rate model, also known as standard cure rate model (Boag, 1949). In this model we assume that a certain fraction of the population are cured and the remaining are not cured (Maller and Zhou, 1996). In order to model cure fraction, parametric and non-parametric methods are used in this approach (Achcar et al., 2012). Second approach which was introduced by Chen et al in 1999 is the non-mixture cure rate model (Chen et al., 1999), also known as bounded cumulative hazard model and promotion time cure model (Tsodikov et al., 2003; Tournoud and Ecochard, 2008). As one of the advantages of the non-mixture cure rate model, it has a proportional hazards model (Lambert et al., 2007). In this approach it is assumed that an individual is left with Ni metastaticcomponent cancer cells after treatment (Yakovlev et al., 1996; Tsodikov et al., 2003). In this study we assumed that Ni had a Poisson distribution.

For data analysis, clinical, pathological, and biological characteristics of patients were assessed in the cure model. A Weibull distribution was proposed for the survival time. The data were analyzed using STATA version 14 and the figure was prepared by $\mathrm{R}$ version 3.1.2. Quantitative results were expressed as mean \pm standard deviation. The significance level was set at $\mathrm{P} \leq 0.05$.

\section{Results}

Patients' characteristics are presented in Table 1. A total of 438 women with breast cancer were enrolled into this analysis. The mean of age at the time of diagnosis was $48.36 \pm 10.90$ years. Patients' age ranged from 22

Table 1. Clinical, Pathological, and Biological Characteristics in Patients with Breast Cancer

\begin{tabular}{|c|c|c|}
\hline Factors & No. of patients & Percentage $(\%)$ \\
\hline \multicolumn{3}{|l|}{ Age at diagnosis } \\
\hline Under 40 yrs. & 88 & 20.09 \\
\hline 40 to $70 \mathrm{yrs}$. & 336 & 76.71 \\
\hline Over 70 yrs. & 14 & 3.2 \\
\hline \multicolumn{3}{|l|}{ Education } \\
\hline Illiterate & 37 & 8.45 \\
\hline Elementary school & 51 & 11.64 \\
\hline Secondary school & 53 & 12.1 \\
\hline Diploma & 161 & 36.76 \\
\hline Academic & 136 & 31.05 \\
\hline \multicolumn{3}{|l|}{ Marital } \\
\hline Single & 24 & 5.48 \\
\hline Married & 414 & 94.52 \\
\hline \multicolumn{3}{|l|}{ Abortion } \\
\hline Yes & 153 & 34.93 \\
\hline No & 285 & 65.07 \\
\hline \multicolumn{3}{|l|}{ Breastfeeding } \\
\hline Yes & 381 & 86.99 \\
\hline No & 57 & 13.01 \\
\hline \multicolumn{3}{|l|}{ Family history } \\
\hline Yes & 124 & 28.31 \\
\hline No & 314 & 71.69 \\
\hline \multicolumn{3}{|l|}{ Type of surgery } \\
\hline $\mathrm{BCS}$ & 274 & 62.56 \\
\hline MRM & 164 & 37.44 \\
\hline \multicolumn{3}{|l|}{ Lymph node status } \\
\hline No & 198 & 45.21 \\
\hline N1 & 121 & 27.63 \\
\hline $\mathrm{N} 2$ & 39 & 8.9 \\
\hline N3 & 80 & 18.26 \\
\hline \multicolumn{3}{|l|}{ Tumor size } \\
\hline $\mathrm{T} 1$ & 111 & 25.34 \\
\hline $\mathrm{T} 2$ & 242 & 55.25 \\
\hline $\mathrm{T} 3$ & 85 & 19.41 \\
\hline \multicolumn{3}{|l|}{ Stage } \\
\hline I & 96 & 21.92 \\
\hline II & 193 & 44.06 \\
\hline III & 135 & 30.82 \\
\hline IV & 14 & 3.2 \\
\hline \multicolumn{3}{|l|}{ Histologic grade } \\
\hline Well differentiated & 47 & 10.73 \\
\hline Moderately differentiatec & ted 235 & 53.65 \\
\hline Poorly differentiated & 156 & 35.62 \\
\hline \multicolumn{3}{|l|}{ Estrogen Receptor } \\
\hline Positive & 312 & 71.23 \\
\hline Negative & 126 & 28.77 \\
\hline \multicolumn{3}{|l|}{ Progesterone Receptor } \\
\hline Positive & 288 & 65.75 \\
\hline Negative & 150 & 34.25 \\
\hline \multicolumn{3}{|l|}{ Lymphovascular Invasion } \\
\hline Positive & 172 & 39.27 \\
\hline Negative & 266 & 60.73 \\
\hline \multicolumn{3}{|l|}{ Recurrence } \\
\hline Yes & 70 & 15.98 \\
\hline No & 368 & 84.02 \\
\hline
\end{tabular}




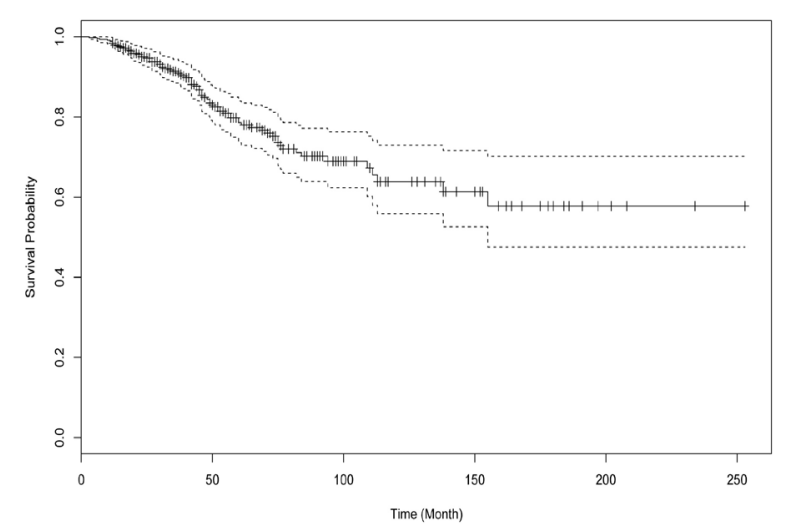

Figure 1. Kaplan-Meier Survival Curve of the Entire Study Population

Table 2. Estimation Based on Non-mixture Cure Rate Model

\begin{tabular}{|c|c|c|c|}
\hline Factors & HR & $\mathrm{SD}$ & P-value \\
\hline \multicolumn{4}{|l|}{ Age at diagnosis } \\
\hline Under 40 yrs. & 0.7 & 1.504 & 0.642 \\
\hline 40 to 70 yrs. & 1.951 & 1.466 & 0.183 \\
\hline Over 70 yrs. $* *$ & 1 & & \\
\hline \multicolumn{4}{|l|}{ Marital } \\
\hline Single & 0.898 & 1.371 & 0.512 \\
\hline Married ** & 1 & & \\
\hline \multicolumn{4}{|l|}{ Abortion } \\
\hline Yes & 0.666 & 0.498 & 0.181 \\
\hline $\mathrm{No}^{* *}$ & 1 & & \\
\hline \multicolumn{4}{|l|}{ Breastfeeding } \\
\hline Yes & 0.614 & 0.782 & 0.432 \\
\hline No $* *$ & 1 & & \\
\hline \multicolumn{4}{|l|}{ Family history } \\
\hline Yes & 0.18 & 0.53 & 0.735 \\
\hline No $* *$ & 1 & & \\
\hline \multicolumn{4}{|l|}{ Type of surgery } \\
\hline BCS & 0.952 & 0.49 & 0.052 \\
\hline $\operatorname{MRM} * *$ & 1 & & \\
\hline \multicolumn{4}{|l|}{ Lymph node status } \\
\hline NO & 3.099 & 1.022 & $0.002 *$ \\
\hline N1 & 1.737 & 0.78 & $0.026 *$ \\
\hline $\mathrm{N} 2$ & 0.514 & 0.791 & 0.516 \\
\hline $\mathrm{N} 3 * *$ & 1 & & \\
\hline \multicolumn{4}{|l|}{ Stage } \\
\hline I & 1.662 & 1.905 & 0.383 \\
\hline II & 2.272 & 1.804 & 0.208 \\
\hline III & 2.434 & 1.689 & 0.149 \\
\hline $\mathrm{IV} * *$ & 1 & & \\
\hline \multicolumn{4}{|l|}{ Histologic grade } \\
\hline Well differentiated & 4.067 & 1.74 & $0.019 *$ \\
\hline Moderately differentiated & 1.508 & 0.561 & $0.007 *$ \\
\hline Poorly differentiated $* *$ & 1 & & \\
\hline \multicolumn{4}{|l|}{ Estrogen Receptor } \\
\hline Positive & 0.423 & 0.727 & 0.56 \\
\hline Negative $* *$ & 1 & & \\
\hline \multicolumn{4}{|l|}{ Progesterone Receptor } \\
\hline Positive ** & 1 & & \\
\hline Negative & 0.1 & 0.706 & 0.887 \\
\hline \multicolumn{4}{|l|}{ Lymphovascular Invasion } \\
\hline Positive $* *$ & 1 & & \\
\hline Negative & 0.319 & 0.498 & 0.522 \\
\hline
\end{tabular}

to 84 years. The longest duration of follow-up was 253 months. A total of 75 patients $(17.08 \%)$ died due to breast cancer during the study up to October 2014. The KaplanMeier observed curve, with $95 \%$ confidence interval, is illustrated in Figure 1. As the Figure shows, the curve reached a plateau at the right tail, so using the cure rate model led to more accurate results. The prognostic variables included in the model were age at diagnosis, marital status, history of abortion, history of breastfeeding, family history of breast cancer, type of surgery, number of metastatic lymph nodes, tumor size, stage, histologic grade, estrogen receptor, progesterone receptor, and lymphovascular invasion. According to the results which are presented in Table 2, number of metastatic lymph nodes and histologic grade were significant. In addition cure fraction was estimated to be $58 \%$.

\section{Discussion}

One of the appropriate and useful ways to investigate any progresses in cancer therapy is to monitor trends in survival of patients over time (Bakar et al., 2008). The time from diagnosis until occurrence of a specific event under study is the most valuable measure of care for patients, clinicians, and even policy makers (Andersson et al., 2011). Therapies for many types of diseases especially cancers have been improved significantly in the recent years, so we are facing an increase in the proportion of patients who do not experience the event under study, i.e. those who are not susceptible to the occurrence of the event under study (Asano et al., 2014). The proportion of such observations is known as cure fraction. In addition, survival analysis via considering cure fraction is called cure rate models or long-term survival models and they perform a considerable function in survival analysis (Ortega et al., 2014).

For the past 20 years or more, several studies have been conducted on cure rate models and they have been well developed in the statistical literature (Rama et al., 2010; Achcar et al., 2012; Othus et al., 2012; Akhlaghi et al., 2013; Yu et al., 2013; Rahimzadeh et al., 2014), but the models are not common in all fields. More specifically, most of them are focused on cancers-related subjects. For cancers in which some cases may have long-term survival, cure rate models can be an interesting approach to characterize and study the survival of patients. It is worth mentioning that cure rate models are studied because of their optimal properties which may better explain the responses to the variables at different times (Akhlaghi et al., 2013). There are two general types of cure models, mixture and non-mixture. Mixture cure rate models may fit some data better than non-mixture and vice versa (Othus et al., 2012), however in this report we only study the non-mixture cure rate model. Non-mixture cure rate model can explain remaining cancer cells after therapy by using latent variable (Rahimzadeh et al., 2014).

Breast cancer is the first common cancer and the third leading cause of death among Iranian women (Sadjadi et al., 2005); in addition, it's mortality is still lower than that in Western industrialized countries (Taghavi et al., 2012). The aim of this study was to find factors that may have 
an effect on the survival of patients with breast cancer including clinical, pathological, and biological variables. Based on our findings, the number of metastatic lymph nodes and histologic grade were significant. In our study a Weibull distribution was proposed for survival time but it was not restricted to Weibull and some other lifetime distributions could be also considered (Borges et al., 2012); However, Jafari-Koshki's study indicated that cure model with Weibull distribution had the smallest DIC in their report and fitted the data best (Jafari-Koshki et al., 2014). In our study we used logistic link function; as a matter of fact, determining the link function is important because it leads to different assumptions about the joint effect of covariates (Lambert et al., 2007).

Most of the studies on cure models are conducted on prostate or breast cancers, but Sposto used mixture and non-mixture cure models to analyze children's cancer group data (Sposto, 2002). The majority of studies investigating the factors affecting the survival of patients with breast cancer mainly used Log-rank test and Cox analysis. Rahimzadeh's study indicated that in the survival analysis of breast cancer patients with cure rate model, metastasis and stage had a significant effect (Rahimzadeh et al., 2014). In this study data for some clinical, pathological, and biological variables were missing and some were recorded in a wrong way so that they had become useless. In addition, our study was carried out based on the data collected from a single institution; large sample size is one of the desirable properties required for cure models, and can reduce the problems related to convergence and fit of the model (Jafari-Koshki et al., 2014). Nevertheless, in our study the model converged after a few iterations. It is recommended to conduct further studies by assuming other distributions rather than Poisson for $\mathrm{Ni}$ and Weibull for lifetime.

\section{Acknowledgements}

It's notable that the paper is extracted from MSc thesis of Sahar Saeedi Moghaddam in Biostatistics. The research was financially supported by Cancer Research Center in Shahid Beheshti University of Medical Sciences. Also, we would like to thank Cancer Research Center's staff for their whole hearted cooperation during data gathering. Finally, we would like to extend our unlimited gratitude to Dr. Maryam Khayamzadeh for her valuable comments and kind consultations.

\section{References}

Abu Bakar MR, Salah KA, Ibrahim NA, et al (2008). Cure fraction, modelling and estimating in a population-based cancer survival analysis. Malaysian J Mathematical Sciences, 2, 113-34.

Achcar JA, Coelho-Barros EA, Mazucheli J (2012). Cure fraction models using mixture and non-mixture models. Tatra Mountains Mathematical Publications, 51, 1-9.

Akhlaghi AA, Najafi I, Mahmoodi M, et al (2013). Survival analysis of iranian patients undergoing continuous ambulatory peritoneal dialysis using cure model. J Research in Health Sci, 13, 32-6.
Andersson TM, Dickman PW, Eloranta S, et al (2011). Estimating and modelling cure in population-based cancer studies within the framework of flexible parametric survival models. BMC Med Res Methodol, 11, 96.

Arano I, Sugimoto T, Hamasaki T, et al (2010). Practical application of cure mixture model for long-term censored survivor data from a withdrawal clinical trial of patients with major depressive disorder. BMC Med Res Methodol, 10, 33 .

Asano J, Hirakawa A, Hamada C (2014). Assessing the prediction accuracy of cure in the Cox proportional hazards cure model: an application to breast cancer data. Pharmaceutical statistics, 13, 357-63.

Boag JW (1949). Maximum likelihood estimates of the proportion of patients cured by cancer therapy. Journal of the Royal Statistical Society. Series B (Methodological), 11, 15-53.

Borges P, Rodrigues J, Louzada F, et al (2012). A cure rate survival model under a hybrid latent activation scheme. Statistical methods in medical research, 0962280212469682.

Chen M-H, Ibrahim JG, Sinha D (1999). A new Bayesian model for survival data with a surviving fraction. Journal of the American Statistical Association, 94, 909-19.

Corbière F, Joly P (2007). A SAS macro for parametric and semiparametric mixture cure models. Computer Methods And Programs In Biomedicine, 85, 173-80.

Cox DR (1972). Regression models and life tables (with discussion). journal of the royal statistical society, series b, 34, 187-220.

Jafari-Koshki T, Mansourian M, Mokarian F (2014). Exploring factors related to metastasis free survival in breast cancer patients using bayesian cure models. Asian Pac J Cancer Prev, 15, 9673.

Kim S, Zeng D, Li Y, et al (2013). Joint Modeling of longitudinal and cure-survival data. J Statistical theory and Practice, 7 , 324-44.

Lambert PC (2007). Modeling of the cure fraction in survival studies. Stata Journal, 7, 351.

Lambert PC, Thompson JR, Weston CL, et al (2007). Estimating and modeling the cure fraction in population-based cancer survival analysis. Biostatistics, 8, 576-94.

Maller RA, Zhou X 1996. Survival Analysis with Long-Term Survivors, Wiley.

Ortega EM, Barriga GD, Hashimoto EM, et al (2014). A new class of survival regression models with cure fraction. J Data Science, 12, 107-36.

Ortega EM, Cancho VG, Lachos VH (2008). Assessing influence in survival data with a cure fraction and covariates.

Othus M, Barlogie B, LeBlanc ML, et al (2012). Cure models as a useful statistical tool for analyzing survival. Clinical Cancer Research, 18, 3731-6.

Rahimzadeh M, Baghestani AR, Gohari MR, et al (2014). Estimation of the cure rate in Iranian breast cancer patients. Asian Pac J Cancer Prev, 15, 4839-42.

Rama R, Swaminathan R, Venkatesan P (2010). Cure models for estimating hospital-based breast cancer survival. Asian Pac J Cancer Prev, 11, 387-91.

Rondeau V, Schaffner E, Corbière F, et al (2013). Cure frailty models for survival data: Application to recurrences for breast cancer and to hospital readmissions for colorectal cancer. Statistical Methods in Medical Research, 22, 243-60.

Sadjadi A, Nouraie M, Mohagheghi Mohammad A, et al (2005). Cancer occurrence in Iran in 2002, an international perspective. Asian Pac J Cancer Prev, 6, 359.

Schmidt $P$, Witte AD (1989). Predicting criminal recidivism using 'split population'survival time models. J Econometrics, 40, 141-59.

Sposto R (2002). Cure model analysis in cancer: an application 

to data from the Children's Cancer Group. Statistics in Medicine, 21, 293-312.

Taghavi A, Fazeli Z, Vahedi M, et al (2012). Increased trend of breast cancer mortality in Iran. Asian Pac J Cancer Prev, 13, 367-70.

Tournoud M, Ecochard R (2008). Promotion time models with time changing exposure and heterogeneity: application to infectious diseases. Biometrical Journal, 50, 395-407.

Tsodikov A, Ibrahim J, Yakovlev A (2003). Estimating cure rates from survival data: An alternative to two-component mixture models. J Am Statistical Association, 98.

Yakovlev AY, Tsodikov AD, Asselain B 1996. Stochastic models of tumor latency and their biostatistical applications, OECD Publishing.

Yu B (2008). A frailty mixture cure model with application to hospital readmission cata. Biometrical J, 50, 386-94.

Yu X, De Angelis R, Andersson TM, et al (2013). Estimating the proportion cured of cancer: some practical advice for users. Cancer Epidemiol, 37, 836-42. 